\title{
A STUDENT'S TAKE ON EDUCATION IN THE MARITIME INDUSTRY
}

\author{
J-B R G Souppez, Southampton Solent University, UK.
}

\section{SUMMARY}

Building on the personal academic cursus of the author, three leading courses in the marine industry will be introduced and reviewed, namely the Diploma in Practical Boatbuilding at the International Boatbuilding Training College, the BEng (Hons) in Yacht and Powercraft Design at Southampton Solent University, and the MEngSt in Yacht Engineering at the University of Auckland. Particular emphasis will be given to the links between those courses and the industry, and their recent implementations to maximise graduate's employability. In order to illustrate the benefits of modern virtual learning environments, the case study of an eight month full-time distance learning research project realized in collaboration with two radically opposed academic institutions across the globe will be presented.

\section{INTRODUCTION}

The marine industry offers a range of courses, from practical to analytical, some well-established while others have recently been introduced. In all cases, employability has become a primary concern, and institutions are working towards building stronger relations with their local industry, as well as providing greater value for money to the students.

Firstly, the Practical Boatbuilding Diploma offered at the International Boatbuilding Training College in Lowestoft, UK, will be presented, followed the BEng (Hons) Yacht and Powercraft Design taught at Southampton Solent University, UK, and the newly created MEngSt Yacht Engineering at the University of Auckland, New Zealand. All three courses have recently revised and modernised their syllabus to better reflect the needs of their respective industries, thus ensuring graduates are fit for employment.

Subsequently, the case study of a full-time commercial academic project submitted to the University of Auckland and realised in partnership with the International Boatbuilding Training College will demonstrate the feasibility of academic distance learning, despite factors such as the geographical separation and the time difference, thanks to modern means of communications and the ever developing virtual learning environments offered in the higher education.

\section{DIPLOMA IN PRACTICAL BOAT- BUILDING}

\subsection{AN OUTLINE OF THE COURSE}

Established in Lowestoft since 1975, the International Boatbuilding Training College (IBTC) has been at the heart of the conservation of traditional wooden boatbuilding skills. The 47 weeks course leads to an internationally recognised Diploma in Practical Boatbuilding, as well as a City and Guilds (level 3) certificate in Marine Construction, Systems Engineering and Maintenance.
The success of the course relies on its hands-on approach and the wide variety of crafts available for teaching purposes, as well as the addition of multiple short courses focussed on specific aspects of the traditional boatbuilding industry.

\subsection{COURSE CONTENT}

The syllabus starts with a 12 weeks woodworking and joinery course, aiming at bringing students to the desired level of skills and confidence before moving onto actual boatbuilding. The following 35 weeks are primarily dedicated to practical boatbuilding tasks, with short theory and specialised courses in intermittence, for a cumulative total of four weeks. The various modules are divided into three categories: compulsory ones that must be completed to obtain the diploma, desirable ones undertaken if time permits, and additional modules on larger work (suck as backbone, spar making and large structural components) depending on the availability of the tasks. The detailed syllabus of the diploma is presented in Table 1.

\begin{tabular}{|l|l|}
\hline \multirow{4}{*}{} & Woodworking skills \\
\cline { 2 - 3 } & Boat joinery \\
\cline { 2 - 3 } & Jib \& pattern making \\
\cline { 2 - 3 } & Clinker planking \\
\cline { 2 - 3 } & Carvel planking \\
\cline { 2 - 3 } & Repair \& restoration techniques \\
\cline { 2 - 3 } & Snagging \\
\cline { 2 - 3 } & Fitting out \\
\cline { 2 - 3 } & Timbers \\
\cline { 2 - 3 } & Dinghy fit out \\
\cline { 2 - 3 } & Lofting theory \\
\cline { 2 - 3 } & Painting \& varnishing \\
\cline { 2 - 3 } & Caulking \\
\hline & Conservation awareness \\
\hline
\end{tabular}




\begin{tabular}{|c|c|}
\hline \multirow{8}{*}{$\begin{array}{l}\frac{0}{0} \\
\stackrel{\pi}{0} \\
\tilde{\omega} \\
0\end{array}$} & GRP, laminating \& repair \\
\hline & Fixing hull and deck fittings \\
\hline & $\begin{array}{l}\text { Understanding boat drawings and elements } \\
\text { of design }\end{array}$ \\
\hline & Plumbing \& electrics \\
\hline & Boat support and movement \\
\hline & Lofting practical \\
\hline & Splicing \& knotwork \\
\hline & Commercial awareness \\
\hline \multirow{5}{*}{ 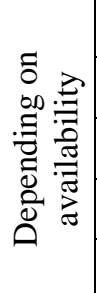 } & Spar making \\
\hline & Backbone \\
\hline & Major structural components \\
\hline & Deck sub structure \\
\hline & Deck laying \\
\hline
\end{tabular}

Table 1: IBTC Practical Boatbuilding Diploma Syllabus.

\subsection{INDUSTRY LINKS}

\section{3 (a) An Industry-Orientated Course}

In addition to being managed as a professional commercial boatyard would be, the course is industryorientated in its syllabus, with both new build and restoration projects to reflect the demands of the niche market that traditional wooden boatbuilding is. Furthermore, a number of manufacturers ranging from timber merchants to resin manufacturers are invited for guest lectures. As a result, students are aware of the links with other industry stakeholders, and more able to set up their own business after the course, which is strongly encouraged and the preferred professional orientation for many graduates. Finally, the excellent reputation of the course built over the years ensures a high employability for the graduates internationally.

\section{3 (b) Shipshape Hub}

The IBTC Lowestoft is also the regional Shipshape Hub, which works in close collaboration with the boatbuilding industry in East Anglia. Shipshape Hubs have been introduced by the National Historic Ships UK organisation in 2010 to promote the local industry and projects inherent to traditional boatbuilding. By becoming a Shipshape Hub, the IBTC Lowestoft ensures a predominant local implantation and employment opportunities for its graduates.

\section{3 (c) New Portsmouth Branch}

Strong of the experience acquired in Lowestoft, the IBTC opened a new branch in Portsmouth historic dockyard, with the first cohort of students starting the 47 weeks course in April 2015. This new location, in an area where the yachting industry is particularly strong, coupled with the increased public exposure of the historic dockyard will further promote the conservation of traditional maritime skills.

The new IBTC Portsmouth is also looking to modernise its syllabus to meet current industry needs. In addition to the traditional carvel and clinker boats, modern construction will now be undertaken, starting with a strip-planked hull then covered with two layers of mahogany veneers. This represents a considerable step forward in terms of production method and technology, and combines two of the most widely employed modern wooden construction techniques, namely strip planking and cold moulding.

\subsection{CONCLUSIONS}

The practical boatbuilding course offered by the IBTC builds a strong foundation with general woodworking skills then applied to boatbuilding with a hands-on approach. The course also benefits from the local industry in East Anglia for the Lowestoft branch, while the Portsmouth one also gains exposure from its location in the historic dockyard. To maintain its position as a leading traditional boatbuilding course, the IBTC is now looking at incorporating modern construction techniques into its syllabus to answer the demands of its industry.

\section{BENG (HONS) YACHT AND POWER- CRAFT DESIGN}

\subsection{AN OUTLINE OF THE COURSE}

Previously delivered as a Diploma at Southampton Institute, the course became a BEng (Hons) in 2005 with the creation of Southampton Solent University, and exists in two versions: the Yacht and Powercraft Design course more focussed on design, and the Yacht Design and Production one, with a stronger emphasis on production. Note that the latter is a remodelled version of the previous Yacht Production and Surveying course.

The yacht engineering programs at Southampton Solent University benefit from a long established worldwide reputation, conveyed by its numerous alumni across the globe, which contributes to attract a large proportion of international students every year.

\subsection{COURSE CONTENT}

Following a survey of the marine industry commissioned by Southampton Solent University in 2012 [1], the course was redesigned, with a stronger emphasis on practical experience and updated content on the key skills highlighted by the surveyed potential employers from the marine industry, in order to maximise the employability of the graduates. The detailed syllabus for the three years of the BEng (Hons) Yacht and Powercraft 
Design, accredited by the Royal Institution of Naval Architects (RINA), is introduced in Table 2.

\begin{tabular}{|c|c|}
\hline \multirow{6}{*}{$\stackrel{\vec{Z}}{\check{\nu}}$} & Computer aided design (20 CATS) \\
\hline & Marine materials (20 CATS) \\
\hline & Marine production (20 CATS) \\
\hline & Marine systems (20 CATS) \\
\hline & Naval architecture (20 CATS) \\
\hline & Structural mechanics (20 CATS) \\
\hline \multirow{6}{*}{$\stackrel{\sim}{\stackrel{\Xi}{*}}$} & Applied marine systems technology (20 CATS) \\
\hline & Computer aided modelling (20 CATS) \\
\hline & Sailing yacht design (20 CATS) \\
\hline & Motor yacht design (20 CATS) \\
\hline & Resistance and propulsion (20 CATS) \\
\hline & Structural analysis (20 CATS) \\
\hline \multirow{6}{*}{$\stackrel{m}{\stackrel{\varpi}{ٍ ँ ~}}$} & Project (40 CATS) \\
\hline & Structural design for production (20 CATS) \\
\hline & Structural design theory (20 CATS) \\
\hline & Advanced naval architecture (20 CATS) \\
\hline & Computer aided engineering (20 CATS) \\
\hline & $\begin{array}{l}\text { Marine industry work based learning (Option) } \\
\text { (20 CATS) }\end{array}$ \\
\hline
\end{tabular}

Table 2: BEng Yacht and Powercraft Design Syllabus.

The course has also been implemented with a wide range of new practical activities, such as greater involvement in the composite workshop for all students, an induction to sailing, and the RYA powerboat level 2 course. All are aimed at increasing the knowledge and experience of the students in other aspects of the marine industry.

\section{$3.3 \quad$ INDUSTRY LINKS}

\section{3 (a) Part Time Work}

Across all three years of the degree, the University policy is to offer a day a week without lectures. This allows students to benefit from relevant work experience. There are indeed a number of local yacht related companies that have hired students on a part time basis during their studies [1].

Furthermore, relevant work experience is offered to students within the University. In 2012, a dozen of yacht engineering students were involved with the manufacturing of a mould tool for a manned modelled used as part of the ship handling course offered by Southampton Solent University at their Timsbury facility. This particular project supported one student's final year dissertation, and offered a number of others valuable and relevant work experience.

\section{3 (b) Enrichment Weeks}

Southampton Solent University has recently adopted additional teaching weeks for all degrees, entitled enrichment weeks. A total of three enrichment weeks take place throughout the year, where normal teaching is replaced by alternative subjects in order to broaden the knowledge and experience of the students. For the yacht engineering courses, industry guest speakers have been welcomed, and local yard visits have been organised. This is a tremendous opportunity for the course to tighten its links with the local industry, and for the students to learn directly from the marine industry.

\section{3 (c) Work Placements}

Many students gain work experience through summer placement arranged by themselves. Alternatively, Southampton Solent University currently offers an informal summer placement with Sunseeker International, based in Poole [1], where three to four positions are offered to second year students. This not only ensures that students gain work experience and develop contacts within the industry, but generally lead to final year dissertations inspired by their work placement, and eventually future employment with the company.

\section{3 (d) Work Based Learning}

During their third year, students are offered the option to take a work based learning unit. The aim is to develop skills and knowledge of the marine industry thanks to a minimum of a hundred working hours in a relevant yacht engineering company. Both students and employers have been extremely satisfied with the work based learning unit experience in the past [1].

\section{3 (e) Employment Offers}

Thanks to its worldwide reputation, the course attracts many employers, and graduate vacancies are offered to students at the end of their third year.

In addition, the University hired in 2015 a graduate associate, in the form of a tow tank liaison position exclusively reserved to a Southampton Solent University graduate. This opportunity allows a recent graduate to evolve in a professional environment and gain experience, while supporting the university's towing tank activities.

\section{3 (f) Industry Presence}

Southampton Solent University further maximises its presence in the industry with novel projects such a Solent Whisper, launched in 2014. The cutting edge foiling 
catamaran was designed by a former graduate of the Yacht and Powercraft Design course and now lecturer. The Solent Whisper was an opportunity to showcase the design and production facilities available at Southampton Solent University, reinforce its presence among the industry, and gain public exposure.

\subsection{ONLINE RESOURCES}

With the ever increasing opportunities offered by new technologies, the learning process is moving towards a more virtual experience through online resources made available to students. Access to online course materials is available at any time on myCourse, Southampton Solent University's online virtual learning environment (VLE).

Vodcasts have been successfully used in the last few years as part of certain units of the yacht engineering courses [2]. This year, lecture capture technology is being introduced across the University. Lectures can be recorded and then published online for the students to access. This has been particularly well welcomed by students due to the large proportion of international students enrolled in the yacht engineering courses.

Extensive research into the use of lecture capture in higher education [3] demonstrated that the intuitive concern about decreasing attendance in the actual lecture was not justified. Indeed, no indication of a decreasing attendance as a result of lecture capture has been recorded, as the primary use of lecture recordings by the students proved to be exam preparation as well as catching up after an absence.

Furthermore, lecturers are able to monitor the viewings of their lecture recordings. From a teaching point of view, this allows to identify if a student has been watching the same lectures over and over, and thus provide personalised support. It will also help refine the content of the lectures: a large number of students reviewing a specific portion of a lecture may indicate that a longer and more detailed explanation of that particular topic is required. The lecture capture technology will therefore not only enhance the learning, but also the teaching.

A number of online resources and a compete VLE are at the disposition of the students attending Southampton Solent University, thus supporting their learning experience and answering the higher demands and expectations of the students.

\section{$3.5 \quad$ CONCLUSIONS}

Widely recognised as one of the world's best undergraduate degree in Naval Architecture, the BEng (Hons) Yacht and Powercraft Design is increasingly looking towards the future with the aim of maximising the employability of its graduates. This objective involved a survey of potential employers from the marine industry to identify the key skills required in today's industry and implement the course content accordingly. In addition, very strong industry links ensure that professional experience is acquired while studying. Finally, a complete virtual learning environment, now working toward lecture capture, is available to support the students.

\section{MENGST YACHT ENGINEERING}

\subsection{AN OUTLINE OF THE COURSE}

The New Zealand marine industry is omnipresent on the worldwide scene, from carbon fibre racing yachts to aluminium superyachts, and is an important part of the country's economy. Based on the forecasted growth of the marine industry in the country, the University of Auckland launched a new Master of Engineering Studies (MEngSt) in Yacht Engineering [4] to help support the New Zealand marine industry. The program was developed in close relation with the local industry, such as the well-established Yacht Research Unit (YRU) and various manufacturers in the Auckland region.

\subsection{COURSE CONTENT}

The taught MEngSt course is available in two forms: a 120 points (two semesters) one, and a 180 points (three semesters) alternative. The latter is intended for international students having a three years degree. Indeed, four years of studies are required to obtain a degree in New Zealand, as opposed to three years in the UK for instance; the difference in academic systems therefore led to the two different versions of the course. The structure of the 120 points Master is presented in Table 3.

\begin{tabular}{|c|c|}
\hline \multirow{3}{*}{ 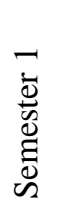 } & Aerodynamics and hydrodynamics (15 points) \\
\hline & Materials and yacht structures (15 points) \\
\hline & $\begin{array}{l}\text { Small craft design and manufacturing (15 } \\
\text { points) }\end{array}$ \\
\hline \multirow{3}{*}{ 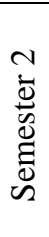 } & $\begin{array}{l}\text { Research Project ( } 15 \text { points in semester } 1,30 \\
\text { points in semester } 2 \text { ) }\end{array}$ \\
\hline & Small craft naval architecture (15 points) \\
\hline & Computational fluid dynamics (15 points) \\
\hline
\end{tabular}

Table 3: MEngSt Yacht Engineering Syllabus.

For the 180 points course, an additional semester is required, and 60 points worth of studies are to be completed. This can either take the form of four learning modules, or a research project; the latter option has been privileged by the author, and will be further discussed in Section 5. 
Note that the 120 points Master is also available as a research course, where all taught units are replaced by a full-time research thesis.

\subsection{INDUSTRY LINKS}

\section{3 (a) Yacht Research Unit}

The Yacht Research Unit was created in 1987 to answer the research interests triggered by the first participation of New Zealand in the America's Cup. In 1993, the intention of Team New Zealand to challenge the current America's Cup defender led to the development of a twisted flow wind tunnel for testing yacht sails [5]. The facility opened in July 1994, and New Zealand went on to win the 1995 and 2000 America's Cup.

The twisted flow wind tunnel remains a predominant part of the YRU, and was logically added to the new Master developed by the University of Auckland. Students are therefore involved with aerodynamic testing as part of the taught syllabus, and are given the opportunity to undertake wind tunnel based research as a research project.

\section{3 (b) Local Industry}

The course being purposely designed to support the New Zealand marine industry, it is no surprise that a number of internationally renown companies based in the Auckland region take part in the course. During the first semester, the Small craft design and manufacturing unit is heavily based on industry visits and lectures. The following companies were involved during the 2014 academic year:

- $\quad$ Alloy Yacht, luxury superyacht builder.

- McMullen and Wing, bespoke luxury yachts builder.

- Yachting Development Limited, composite new- build and refit.

- $\quad$ Rayglass, composite powerboat manufacturer.

- Southern Spars, carbon fibre spars manufacturer.

- $\quad$ North Sails, sails design and manufacturing.

The combination of visits and lectures on a topic inherent to the activity of the company offers valuable insights into the work undertaken in the multiple sectors of the New Zealand marine industry. This is a unit that is particularly well received by the students, and enables to relate the studied materials with their practical industry applications. In addition, by promoting the activities within the local area, students are exposed to employment opportunities in New Zealand, the original intent of the course being to support the future growth of the country's industry.

\section{3 (c) Guest Lecturers}

The Yacht Engineering Master welcomes a number of guest lectures such as professors from other institutions or local composite experts, while also benefiting from the local conferences, such as the events organised by the New Zealand branch of RINA or the High Performance Yacht Design conference.

Furthermore, world renown superyacht designer Ron Holland takes part in the course for a week every academic years, with a number of lectures, as well as a guided visit of Alloy Yachts and onboard one of its $50 \mathrm{~m}+$ superyacht based in Auckland. This is a tremendous opportunity for the students, and encapsulates the whole design process, starting with the designer, moving onto the shipyard, and finally to the finished product, its owner and operation.

\subsection{ONLINE RESOURCES}

CECIL is the University of Auckland's VLE, the name being derived from Computer Supported Learning (CSL). It is extensively used by both students and staffs, and provides a platform to access lecture materials, grades and feedback, as well as lecture recordings.

Indeed, lecture capture technology built-in the class rooms allows all lectures to be recorded and then published on the VLE for the students to consult.

An interesting feature is the notification system linked to the university-provided student email accounts. As important announcements are published on the VLE, students are immediately made aware by email, ensuring fast and efficient communication, also encouraging the students to refer to the VLE more frequently.

\subsection{CONCLUSIONS}

Recently introduced to specifically answer the needs of the New Zealand marine industry, the MEngSt in Yacht Engineering offered by the University of Auckland benefits from very strong ties with the industry, leading to an increased student experience. High profile guest lecturers and the close relations with the Yacht Research Unit also contribute to a more industry-orientated formation to later promote employability. The advanced VLE allows for an enhanced approach to online studies, as well as alternative learning experiences, such as distance learning. This will be presented in the following section in the form of the case study of a full-time academic research project for the University of Auckland, realised for a client and in partnership with the IBTC Lowestoft, both located in the UK. 


\section{CASE STUDY: DISTANCE LEARNING COMMERCIAL RESEARCH PROJECT}

\subsection{AN OUTLINE OF THE PROJECT}

The design brief was to conceive the next generation of Thames A Rater, a centenary old racing class that has now moved to very high aspect ratio carbon rigs. The intent for the customer was to introduce the class to a new location, namely the Norfolk Broads on the East coast of England, and have the boats manufactured at the IBTC Lowestoft. The boat was therefore to be designed for a particular shipyard, with a precise area of operation, and under the Thames A Rater class rules [6]. The challenge was to create a traditional looking yacht that would carry on the historical legacy of the class, while incorporating the latest design and production methods to achieve a competitive racing boat.

\subsection{DISTANCE LEARNING CONSIDERATIONS}

This project was undertaken as a research project during the additional third semester of the course, imposed by the differences in academic systems between the UnitedKingdom and New Zealand previously introduced in section 4.2. Being a research project, no formal teaching would take place at the University of Auckland, with the exception of weekly meetings with an academic supervisor. The design nature of the project implied that no specific research facilities available at the University of Auckland were required, and the need for academic supervision was to a certain extent lesser than for an experimental research project.

The two main stakeholders for the project, namely the client and the shipyard, being based in the UK, communication was identified as a potential issue at a very early stage of the project. Indeed, the 13 hours time difference meant that it would be difficult to efficiently discuss in a timely manner the multiple design and production options for the project.

In this particular example, the client and shipyard having a greater and more critical input into the project compared to the academic supervisor, the decision was made to conduct this project from Europe, effectively leading to a distance learning Master's research project. This decision was agreed to by the supporting academic staff who also identified the necessity of distance learning for this particular project, easily achievable thanks to the VLE and modern communication via internet.

As a result, face to face meetings with the client and visits to the shipyard were easily organised, and fast communication was possible. On the other hand, weekly meetings with an academic supervisor were replaced with email communication, which proved very convenient, and the delays in answering due to the time difference was never a critical issue.
The decision to conduct this project some $18500 \mathrm{~km}$ away from where it would be submitted for assessment also opened new opportunities. Indeed, the Thames A Rater being based in the UK, it enabled to view boats and interact with the sailors to gain feedback and incorporate their requirements into the design.

Finally, presence in the UK would have been required at some point during this project. Indeed, the Thames A Rater class rule [6] imposes that the hull of any new boat is to be an exact replica (with a one and a half inch tolerance) of an original one. An original linesplan of a Thames A Rater was therefore to be obtained, but none are freely available, with the exception of the linesplan of Scamp, designed by Linton Hope in 1902, and conserved in the eleventh edition of Dixon Kemp's manual of yacht and boat sailing and yacht architecture [7] at the British library in London. This document was the keystone of the project, as it allowed for the design to comply with the relevant class rule, and further justified the decision to conduct the project from Europe.

\section{$5.3 \quad$ RESULTS}

The realisation of this distance learning commercial research project proved very successful, from both a commercial and academic perspective.

On the one hand, the opportunity to meet the client face to face and better discuss the design allowed for a refined design brief, eventually leading to a higher quality custom design meeting the clients expectations. Extracts from the formal feedback received from the client to be included in the academic report [8] are presented hereafter and demonstrated the high level of satisfaction achieved:

"Speaking as a yachtsman, businessman (and client for
your design!) I have read through your dissertation
several times and I think it is an exceptional piece of
work. For me, yachts should be safe, fun, fast, affordable,
aesthetically pleasing and manoeuvrable. It is my
considered opinion that your design project has easily hit
the mark in respect of all these areas. [...] This,
therefore, creates a winning design that will keep pace
with the owners competence and sailing ability. [...] It is
my intent to use this design to advance the concept of
classic sailing yachts on The Norfolk Broads in a way
that offers owners the experience of sailing beautiful
contemporary yachts that owe their existence to a
traditional design."

From an academic point of view, the distance learning experience was also very successful. The research project submitted was defined as "an excellent report, well written and very comprehensive", and was awarded the highest mark of $100 \%$, thus illustrating the level satisfaction of the academic staff, and demonstrating the feasibility of such distance learning research projects. 
The project also succeeded in answering the different expectations of the two radically different academic institutions involved. Advanced analytical work and a high standard of academic writing were required for the submission to the University of Auckland. Conversely, the IBTC, intended shipyard for the construction, had its primary interests in practical production consideration and clear construction drawings.

\subsection{CONCLUSIONS}

The case study of a distance learning commercial project as part of an academic qualification at the University of Auckland has been presented, highlighting the greater need for proximity with the client and primary stakeholders of the project as opposed to the academic staff in this instance. Such a project can only be conducted thanks to the virtual learning environment provided by the University and the modern means of electronic communication.

If the project had been conducted from New Zealand, where the academic institution is, as opposed to the UK where both the client and the shipyard are located, it is believed it would not have attained the same level of success. No direct interaction with the client meant a less detailed design brief and precious time lost in communication; and potentially not meeting the class rule since key data to comply was only available in the UK, thus leading to a lower quality design for the client, which would have been reflected on the academic grading. Finally, from a student's perspective, this resulted in a greater experience with additional professional and academic learning outcomes, and therefore a high student satisfaction, which should be the primary focus of higher education.

This novel experiment for the Yacht Engineering program proved very successful, and will certainly open new perspectives for distance learning in the future such as off-site research or industry-linked design projects.

\section{CONCLUSIONS}

The review of some of the leading academic courses in the marine industry, respectively delivered at the International Boatbuilding Training College, Southampton Solent University and the University of Auckland revealed the importance of the links with the industry. This was further highlighted by looking at the recent developments made in all three courses, revolving around stronger relations with the local industry to answer the concerns about graduate employability and maintain their leading status. The ability for a course to tighten the bonds with the marine industry is therefore key to its success.

Based on a full-time research project undertaken for a client in close partnership with the International Boatbuilding Training College and to be submitted as part of a Master at the University of Auckland, new insights into distance learning were gained. The physical location proved to be essential in the realisation of this particular design project, and proximity with the client, shipyard and intended area of operation of the yacht superseded the academic supervision, especially due to the large time difference between the United-Kingdom and New Zealand. The key to a successful distance learning research project therefore lies in identifying the primary stakeholders.

Finally, it is worth noting that such a project can only be made possible with the support of modern electronic means of communication and virtual learning environments made available to the students by academic institutions.

\section{REFERENCES}

1. BARKLEY, G. S., 'Attracting \& Equipping Yacht Design and Production Graduates for Employment in Today's Yacht Design \& Manufacturing Industry', Proceedings of the Royal Institution of Naval Architects Seminar on Education \& Professional Development, 2012.

2. FIRTH G. R., 'The Design and Development of a Blended Learning Module in Marine Craft Materials and Production Technology', Proceedings of the Royal Institution of Naval Architects Seminar on Education \& Professional Development, 2012.

3. MAHAL, K., 'Lecture Capture in Higher Education', AMS Report, 2013.

4. FLAY, R. G. J., 'A New Master's Degree in Yacht Engineering at the University of Auckland', Proceedings of the Royal Institution of Naval Architects Conference on Education and Professional Development of Engineers in the Maritime industry, 2013.

5. FLAY, R. G. J., 'A twisted flow wind tunnel for testing yacht sails', Journal of Wind Engineering and Industrial Aerodynamics, 1996.

6 THAMES SAILING CLUB, 'The Thames A Rater Association Rules', Thames Sailing Club, 2007.

7. KEMP, D., 'Dixon Kemp's manual of yacht and boat sailing and yacht architecture', $11^{\text {th }}$ Edition, edited by B. Hoekstall-Smith and L. Hope. London: Horace Cox.

8. Souppez, Jean-Baptiste. Design and Production of a Wooden Thames A Rater Class Sailing Yacht. 2015. 10.13140/RG.2.2.25878.04165. 


\section{AUTHORS BIOGRAPHY}

Jean-Baptiste R. G. Souppez holds the current position of Lecturer in Yacht Design and Composite Engineering at Southampton Solent University. He is responsible for delivering a number of units of the BEng (Hons) Yacht and Powercraft Design and BEng (Hons) Yacht Design and Production. He graduated from the BEng (Hons) in Yacht and Powercraft Design at Southampton Solent University in 2013, from the Diploma in Practical Boatbuilding at the International Boatbuilding Training College in 2014 and from the MEngSt in Yacht Engineering at the University of Auckland in 2015.

\section{DISCLAIMER}

The views and opinions expressed in this paper are solely those of the author, and do not necessarily reflect those of the academic institutions discussed. 